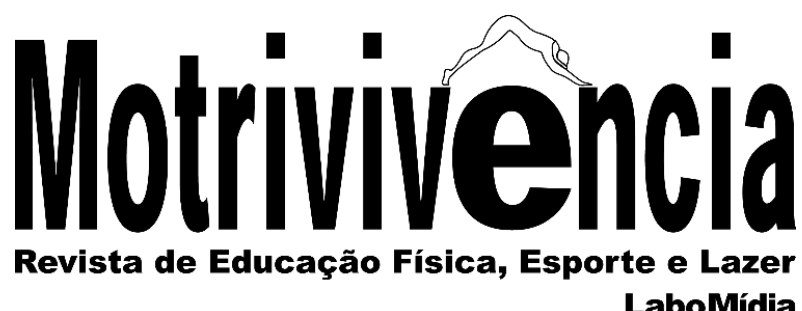

\title{
A produção acadêmico-científica sobre jogos eletrônicos em periódicos da área de Educação Física no Brasil
}

\section{RESUMO}

Dada a recente notoriedade que os estudos dos jogos eletrônicos vêm adquirindo no campo acadêmico, a presente investigação teve como objetivo mapear a produção científica sobre a temática em tela na área da Educação Física. Para atender a tal premissa, localizamos em revistas científicas da área 41 textos que versavam sobre o tema. Por meio de análise descritiva, em consonância com a mobilização do referencial sociológico de Pierre Bourdieu, verificamos que as Revistas Licere e Motrivivência são os principais veículos de divulgação da temática investigada. Face a essa conformação, constatamos também a centralidade da Universidade Federal do Paraná e da Universidade Federal de Santa Catarina como alguns dos principais polos de produção de estudos associados aos jogos eletrônicos no campo da Educação Física no Brasil. Mediante esses dados, concluímos que as redes de relações acadêmicas constituem posições sociais de um campo de investigação, movido e influenciado por um habitus científico.

PALAVRAS-CHAVE: Jogos eletrônicos; Educação física; Produção do conhecimento

\begin{tabular}{|c|}
\hline $\begin{array}{r}\text { Matheus Borsato } \\
\text { Mestre em Educação Física } \\
\text { Universidade Estadual de Maringá - UEM, Educação } \\
\text { Física, Maringá, Paraná, Brasil } \\
\text { mthsbrst@gamail.com } \\
\text { @ }{ }_{\text {https://orcid.org/0000-0003-3943-7376 }}\end{array}$ \\
\hline $\begin{array}{r}\text { Marcos Roberto Brasil } \\
\text { Mestre em Educação Física } \\
\text { Universidade Estadual de Maringá - UEM, Educação } \\
\text { Física, Maringá, Paraná, Brasil } \\
\text { Faculdade Guairacá, Educação Física, Guarapuava, } \\
\text { Paraná, Brasil } \\
\text { brasilmr@hotmail.com.br } \\
1 \text { https://orcid.org/0000-0001-9915-3856 }\end{array}$ \\
\hline $\begin{array}{r}\text { Vinicius Machado de Oliveira } \\
\text { Mestre em Educação Física } \\
\text { Universidade Estadual de Maringá - UEM, Educação } \\
\text { Física, Maringá, Paraná, Brasil } \\
\text { oliveira_vm@hotmail.com } \\
\text { @ https://orcid.org/0000-0003-1789-8243 }\end{array}$ \\
\hline $\begin{array}{r}\text { Verônica Volski Mattes } \\
\text { Mestre em Educaçãa } \\
\text { Universidade Estadual de Maringá - UEM, Educação } \\
\text { Física, Maringá, Paraná, Brasil } \\
\text { Universidade Estadual do Centro Oeste - } \\
\text { UNICENTRO, Educação Física, Guarapuava, } \\
\text { Paraná, Brasil } \\
\text { vero_edf@hotmail.com } \\
\text { @ https://orcid.org/0000-0002-9599-6618 }\end{array}$ \\
\hline $\begin{array}{r}\text { Juliano de Souza } \\
\text { Doutor em Educação Física. } \\
\text { Universidade Estadual de Maringá - UEM, } \\
\text { Maringá, Paraná, Brasil } \\
\text { Observatório Educação Física e Esporte / OEFE } \\
\text { julianoedf@yahoo.com.br } \\
\text { @ https://orcid.org/0000-0003-3491-9536 }\end{array}$ \\
\hline
\end{tabular}




\title{
The academic-scientific production on electronic games in Physical Education journals in Brazil
}

\begin{abstract}
Given the recent notoriety that the studies of the electronic games have been acquiring in the academic field, the present research had the objective of mapping the scientific production on the subject in screen in the area of Physical Education. To meet this premise, we located 41 scientific texts dealing with the topic in scientific journals in the area. Through descriptive analysis in line with the mobilization of the sociological reference of Pierre Bourdieu, we verified that Licere Magazines and Motrivivência Magazines are the main vehicles for disseminating the researched topic. In view of this conformation, we also note the centrality of the Federal University of Paraná and the Federal University of Santa Catarina as some of the main poles of production of studies associated with electronic games in the field of Physical Education in Brazil. From these data, we conclude that the networks of academic relations constitute social positions of a field of investigation, moved and influenced by a scientific habitus.
\end{abstract}

KEYWORDS: Electronic games; Physical education; Production of knowledge

\section{La producción académico-científica sobre juegos electrónicos en revistas de Educación Física en Brasil}

\section{RESUMEN}

Dada la reciente notoriedad que los estudios de los juegos electrónicos vienen adquiriendo en el campo académico, la presente investigación tuvo como objetivo mapear la producción científica sobre la temática en pantalla en el área de la Educación Física. Para atender a esta premisa, localizamos en revistas científicas del área, 41 textos que versaban sobre el tema. Por medio de un análisis descriptivo en consonancia con la movilización del referencial sociológico de Pierre Bourdieu, se verificó que las Revistas Licere y Motrivivência son los principales vehículos de divulgación de la temática investigada. Frente a esa conformación, constatamos también la centralidad de la Universidad Federal de Paraná y de la Universidad Federal de Santa Catarina como algunos de los principales polos de producción de estudios asociados a los juegos electrónicos en el campo de la Educación Física en Brasil. Mediante esos datos, concluimos, que las redes de relaciones académicas constituyen posiciones sociales de un campo de investigación, movido e influenciado por un habitus cientifico.

PALABRAS-CLAVE: Juegos electrónicos; Educación física; Producción del conocimiento 


\section{INTRODUÇÃO}

O contexto de modernização reflexiva ${ }^{1}$ que vivemos na atualidade, aliado à expansão de um ciberespaço ${ }^{2}$, revela uma nova etapa, na qual a cultura passa a ser mediada pelos meios de interação virtual, fazendo com que os indivíduos cheguem a passar várias horas utilizando equipamentos eletrônicos (AMARAL, 2016) ou, até mesmo, igualando o seu tempo gasto em uma rede social ao tempo médio para se alimentar (STEWART, 2016). Sob esse pano de fundo é que se alicerçou à crescente indústria dos Jogos Eletrônicos (JEs) ou, mais precisamente, dos e-Sports (OLIVEIRA, 2017).

Esses espaços sociais são constituídos, em sua maioria, por jovens e proporcionam um universo marcado por desafios, riscos, tomadas de decisões e aventuras virtuais. Percebemos também que os JEs estão inseridos na dinâmica de individualização dos estilos de vida a que se refere Giddens (2002). Para o autor, os indivíduos não só tendem a desvincularem-se do que é considerado tradicional como, ao mesmo tempo, passam a investir seu tempo em novas maneiras de ser, reinventando, por conseguinte, o mundo social.

Nessa esteira, o crescimento dessa "nova modalidade" potencializa a abertura de uma agenda contemporânea para pesquisadores interessados na produção do conhecimento, levando a criação de um subcampo de investigação científica. Historicamente, o primeiro relato de algo que se assemelha a um videogame remonta ao ano de 1947: um "dispositivo de entretenimento com tubo de raios catódicos”3 criado a partir da tecnologia de radares e patenteado no ano de 1948 por Thomas T. Goldsmith e Estle Ray Mann (ARANHA, 2004). Daquele tempo até os dias de hoje, diversas mudanças a respeito dos JEs ocorreram. A tecnologia dos videogames seguiu um curso de evolução até chegar às quantidades de vertentes eletrônicas que possuímos no século XXI, movimentando cerca de US\$ 66 bilhões em vendas pelo mundo e de, aproximadamente, US\$ 1 bilhão somente no Brasil,

\footnotetext{
${ }^{1}$ Para Beck; Giddens; Lash (1997), a modernização reflexiva é um termo utilizado afim de categorizar a sociedade pós-tradicional. Essa ideia, por seu turno, pode ser encarada a partir do senso do fim de uma época, como pelo senso de um novo começo. Já o conceito de reflexividade representa a possibilidade de reinvenção da modernidade bem como de suas formas industriais.

${ }^{2} \mathrm{O}$ conceito de ciberespaço pode ser melhor compreendido a partir da explicação que Pierre Lévy faz sobre o que é virtual (LÉVY, 1996). Segundo o sociólogo, o virtual é uma nova modalidade de ser e sua compreensão torna-se facilitada se também considerarmos o processo que leva a ele: a virtualização.

${ }^{3}$ Também conhecido como cinescópio. Trata-se de uma espécie de válvula utilizada para a visualização de imagens.
} 
ultrapassando - ao menos é o que se estima até o ano de 2019 - as indústrias do cinema e da música juntas (MANCUSO, 2015).

Nesses termos, aos empregarmos os conceitos teóricos do sociólogo francês Pierre Bourdieu (BOURDIEU, 1983, 1990), poderemos dizer que esta indústria de videogames emerge e pode ser dimensionada como um subcampo do campo esportivo, afinal envolve profissionais, espectadores e simpatizantes da área, atrelados, portanto, a um universo relativamente autônomo que é regulado por leis de oferta e demanda. Segundo relatório emitido pela empresa Super Data Research, o faturamento do setor de e-Sports alcançou US\$ 747,5 milhões em 2015 e poderá aumentar cerca de 100\% até o ano de 2019, sendo a maior parte deste lucro advinda de patrocinadores e propagandas, além de apostas e de ligas de fantasia (MACY, 2015).

Tendo em vista, portanto, esse cenário rapidamente esboçado sobre as proporções sociais do fenômeno e também sobre a pluralidade de áreas que se interessam em pesquisálo, o objetivo deste artigo é analisar a produção acadêmico-científica acerca da temática dos JEs em revistas científicas da área de Educação Física no Brasil. De modo a dar conta desse objetivo, organizamos o trabalho em três partes. Na primeira delas, discorremos sobre as decisões teórico-metodológicos adotadas na pesquisa. Em seguida, apresentamos os dados e resultados obtidos. Por fim, trazemos as devidas conclusões pertinentes ao processo analítico reflexivo com base na teoria sociológica de Pierre Bourdieu.

\section{ENCAMINHAMENTOS TEÓRICOS-METODOLÓGICOS}

Em um primeiro momento, com a finalidade de verificar a produção de conhecimento sobre JEs no universo da Educação Física brasileira, realizamos um mapeamento sistemático a partir dos textos completos em seis periódicos científicos em âmbito nacional - Revista Brasileira de Ciência do Esporte (1979-2017), Revista Motrivivência (1988-2017), Revista Movimento (1994-2017), Revista Motriz (1995-2017), Revista Licere (1998-2017) e Revista Pensar a Prática (1998-2017). O recorte temporal adotado abrangeu um total de 38 anos em revisão e análise.

Os critérios para escolha dessas revistas como material empírico, foram os seguintes: [1] acesso a todos os números publicados pelos periódicos, seja na forma digital, ou meio impresso; [2] o ciclo longevo de divulgação acadêmico-científica no campo da Educação Física brasileira; e, por fim, [3] caracterizarem-se como periódicos que 
apresentavam espaço em seu escopo para divulgação das pesquisas de caráter sociocultural em Educação Física.

Após a escolha das revistas científicas, em uma segunda etapa da pesquisa foi realizado de forma direta e manual o download de todos os trabalhos nos próprios sítios dos periódicos, no propósito de constituir-se um banco de dados para investigação. Nesse percurso, foram localizados um total de 8.735 trabalhos, entre artigos originais, artigos de revisão, relatos de experiência, ensaios, resenhas, resumos em anais de eventos, seções e espaços específicos de cada revista investigada. Para o refinamento desse material, o próximo procedimento teórico-metodológico realizado deu-se em torno da aplicação de descritores. Assim sendo, elegemos os seguintes termos: "Jogos Eletrônicos”, “Jogos Virtuais"; "Exergames" e "e-Sports".

A partir dos descritores, encontramos o total de 41 textos que atendiam o perfil de amostra desejado. Ainda nesse cenário, é imprescindível sublinhar que os estudos de revisão sistemática foram suprimidos da presente investigação, pois esses já revisitaram a literatura a partir de outros procedimentos metodológicos que não condizem com os utilizados nesta pesquisa. Uma vez levado a efeito os critérios de inclusão e exclusão dos trabalhos, os textos foram estratificados quanto ao seu gênero: Artigos Originais, Ensaios, Resumos publicados em anais de eventos científicos e Resenhas. Por fim, os textos também foram classificados quanto ao enfoque temático do estudo. Nesse sentido, chegamos a seguinte categorização: Histórico Social, Jogos Digitais, Lazer, Exergames. Cabe mencionar que essas categorias foram desenvolvidas e elencadas pelos próprios autores desse estudo.

$\mathrm{Na}$ primeira categoria, denominada Histórico-Social, são caracterizados trabalhos que tiveram por objetivo verificar a interação humano-máquina produzida pelas gerações dos JEs. Também fazem parte desta categoria estudos dos impasses epistemológicos provocados por mudanças socioculturais da cibercultura; práticas corporais e experiência com a virtualização; desenvolvimento das tecnologias informáticas e relação entre jogos digitais e cultura.

A segunda categoria desenvolvida foi denominada Jogos Digitais. Nesse grupo, foram dispostos estudos em que os objetos investigados tiveram uma relação direta ou uma experiência com algum jogo em específico. Ademais, nessa categoria, foram elencados estudos em que ocorreu a transferência de aprendizagem do ambiente virtual para o contexto real. 
Já a terceira categoria foi classificada como estudos no âmbito do Lazer. Nesse grupamento fizeram parte pesquisas que compreendiam os JEs como uma atividade alocada no campo do lazer, ou seja, como práticas inseridas em um contexto de ludicidade e de prazer. Por fim, a última categoria avaliada foi a de estudos compreendidos como Exergames. Nessa categoria encontram-se aqueles estudos que pesquisam os diversos efeitos da conexão entre o movimento humano com o contexto virtual. Em linhas gerais, os Exergames "são jogos que captam e virtualizam os movimentos reais dos usuários" (BARACHO; GRIPP; LIMA, 2012, p. 111).

Posteriormente à proposta de classificação, e com a finalidade de verificar quem são ou foram os principais agentes a atuar com essa agenda de discussão, o próximo procedimento teórico-metodológico consistiu na realização do agrupamento de todos os autores e coautores dos 41 textos que fazem parte da análise. Logo, foram encontrados um total de 100 pesquisadores. Contudo, devido ao grande número identificado e, com a intenção de buscar os principais agentes a fazer valer essa temática como objeto de estudo, classificamos somente os autores com no mínimo dois trabalhos publicados. Os demais foram agrupados em uma única seção, denominada "outros". Dessa mesma forma, elencamos as Instituições de Ensino Superior (IES), a fim de verificar os principais centros divulgadores e pesquisadores sobre JEs.

Para as análises levadas a efeito ao longo do artigo, mobilizamos a teoria sociológica de Pierre Bourdieu, em especial seus conceitos de campo, capital e habitus. Para compreender a estrutura dos periódicos científicos, inicialmente, utilizamos o conceito teórico de campo. Quando Bourdieu propõe a noção de campo, na verdade, ele se dispõe a desvelar como se dão as posições entre os agentes/estrutura e como tais conhecimentos reproduzem as relações objetivas da sociedade. Assim, as lutas internamente orquestradas no campo refletem rivalidades, ambições e relação de poder entre posições sociais dominantes e dominadas. Em outras palavras, aqueles que se encontram em uma posição superior buscam manter a estrutura e a lógica do jogo, pois estão em uma condição, teoricamente, mais "confortável”. Já aqueles que se encontram em uma posição inferior tentam reverter a dialética do campo (BOURDIEU, 1983; 1990).

Em prosseguimento as análises, utilizamos os conceitos de capital simbólico e capital científico, para observar como é proporcionado aos pesquisadores, por meio de suas publicações em revistas científicas, diferentes tipos de capital. O primeiro conceito é “[...] a noção mais complexa e a mais necessária de compreensão [...]” (BOURDIEU, 2014, p. 352). Nesse particular, destaca-se o capital simbólico como sendo “[...] a forma de capital 
que nasce da relação entre uma espécie qualquer de capital e agentes socializados de maneira a conhecer e reconhecer essa espécie de capital" (BOURDIEU, 2014, p. 352). O capital simbólico, então, como a palavra diz, situa-se na ordem do conhecimento e do reconhecimento. Esse por sua vez “[...] não é outra coisa senão o capital econômico ou cultural quando conhecido e reconhecido [...]” (BOURDIEU, 1990, p. 163). O capital simbólico é uma particularidade específica "[...] (de qualquer tipo de capital, físico, econômico, cultural, social), percebida pelos agentes sociais cujas categorias de percepção são tais que eles podem entendê-las (percebê-las) e reconhecê-las, atribuindo-lhes valor" (BOURDIEU, 1996, p. 107). Assim sendo, o capital simbólico exerce uma forma de atração no campo e tem capacidade de reiterar e impulsionar relações de forças conflitantes em torno da busca por distinção (BOURDIEU, 2014).

Já o segundo conceito, capital científico, está relacionado à legitimidade em um determinado campo. Dentro dessa estrutura, o que está em jogo é a reputação, prestígio, autoridade, competência, notoriedade (uma espécie exclusiva de capital social) que só é assegurada por meio de seus pares-concorrentes. Em um campo altamente autônomo e concorrido, como se faz o campo acadêmico-científico, um agente só pode ser reconhecido por outros cientistas entregues ao mesmo jogo, visto que somente esses possuem os meios simbólicos de apropriarem a produção para avaliar seus méritos e deméritos e, consequentemente, atribuir valor e qualificá-la como legítima ou ilegítima (BOURDIEU, 1983, 2004).

Paralelamente à essa leitura dos capitais investidos no jogo, mobilizamos também o conceito de habitus, procurando identificar o habitus cientifico que circunda o universo de produção sobre os JEs. É importante ressaltar que na teoria de Bourdieu, os conceitos de habitus e de campo constituem uma relação de cumplicidade ontológica (SOUZA; MARCHI JÚNIOR, 2017), uma vez que o campo é formado por relações historicamente construídas e interessadas enquanto o habitus é o resultado dessas contingências manifesto sob a forma de história incorporada e com predisposição para modificar ou não a estrutura (BOURDIEU, 1990, 1997).

Dessa forma, o habitus é formado e construído por meio de vivências datadas no campo, as quais vão se acumulando e se incorporando no agente: "o corpo é o substrato do habitus" um aglomerado de "esquemas generativos" que precedem a ação (ORTIZ, 1983, p. 14). Ademais, o habitus se relaciona com o tecido social, estabelecendo um "conhecimento sem consciência", uma "intencionalidade sem intenção" (BOURDIEU, 1990, p. 24) e regulando um domínio prático de ações. Em suma, esses seriam os principais 
conceitos da teoria bourdieusiana que mobilizamos em nossa pesquisa. Na sequência, passamos a apresentar alguns dos resultados e discussões que foram possíveis a partir desse exercício de confrontação empírico-teórica.

\section{RESULTADOS E DISCUSSÕES}

Ao contextualizar inicialmente os periódicos científicos da área de Educação Física que integram nosso mapeamento sistemático, constatamos que a Revista Licere é o periódico que, até o momento, possui o maior número de artigos sobre JEs. Na sequência, localiza-se a Revista Motrivivência. Em linhas gerais, as publicações desses dois periódicos representam quase a metade $(46,5 \%)$ de todas as publicações sobre os JEs no campo acadêmico-científico da Educação Física no Brasil, ao menos do ponto de vista do alcance empírico de nossa investigação.

Pensando nos periódicos como estrutura de um subcampo de investigação científica da área de Educação Física - referente à temática dos JEs -, poder-se-ia dizer que as Revistas Licere e Motrivivência, dominam essa discussão no campo. Um acontecimento importante que pode lançar luz a essa dinâmica de produção e divulgação do conhecimento “[...] é a questão da distribuição dos poderes e dos privilégios entre as diferentes categorias de agentes engajados nessa concorrência [...]” (BOURDIEU. 1983, p. 42). Em outros termos, trata-se de perceber que os próprios periódicos são detentores da autoridade legítima de impor algumas definições na estrutura do campo, a partir do poder simbólico de fomentar determinadas discussões e de promover determinados objetos que, com o passar do tempo e dos padrões do campo, podem, inclusive, diferenciarem-se tornando seus efeitos mais prolongados e também mais profundos (BOURDIEU, 2001) em termos de capitalização científica e política.

Ademais, tais autoridades, mesmo que de forma involuntária, acabam exercendo uma determinada influência no campo e no habitus dos agentes que compõem essa estrutura. A(s) autoridade(s) legítima(s) moldam a estrutura de poder (algumas vezes em benefício próprio, inclusive) tanto para os dominantes quanto para os dominados, dependendo da lógica e das disputas do campo, além das regras de investimento no jogo deflagrada pela illusio ${ }^{4}$ (BOURDIEU, 1990, 1996, 2007). Em adição, é possível que haja,

\footnotetext{
4 "Illusio na acepção latina do termo designa uma forma particular de interesse e recobrado nesse exato sentido na obra de Pierre Bourdieu significa, portanto, o interesse de estar envolvido no jogo. Em outras palavras, illusio pode ser entendida como o "sentido do jogo" e, nesse caso, se constitui como uma
} 
mesmo entre estruturas e agentes "dominantes" do campo, um jogo de oposições entre si sob a forma caricatural de uma "dominação dos dominantes", regrada pelo acúmulo dos diferentes tipos de capitais que constituem os diferentes tipos de poder (BOURDIEU, 2001, 2013).

A Revista Licere é um periódico do Programa de Pós-Graduação Interdisciplinar em Estudos do Lazer vinculada à Universidade Federal de Minas Gerais. A revista tem como política o livre acesso, que nada mais é que disponibilizar gratuitamente o conhecimento científico ao público. Talvez sua correlação com o campo dos estudos do lazer a torna uma das revistas mais procuradas para a divulgação, bem como para consulta das publicações e submissões de trabalho, sendo ainda, um dos principais meios de divulgação acadêmicocientífico da Educação Física na temática Lazer e, consequentemente, dos JEs quando tratados por via dessa lógica. Os resultados da Revista Licere e dos demais periódicos são apresentados a seguir (Tabela 1).

Tabela 1: Frequência relativa e absoluta do total de trabalhos analisados por periódicos

\begin{tabular}{lcc}
\hline Periódicos Científicos & & $\mathbf{\%}$ \\
\hline Revista Licere & 11 & 26,9 \\
Revista Motrivivência & 08 & 19,6 \\
Revista Brasileira de Ciência do Esporte & 06 & 14,6 \\
Revista Motriz & 06 & 14,6 \\
Revista Movimento & 06 & 14,6 \\
Revista Pensar a Prática & 04 & 09,7 \\
\hline Total & $\mathbf{4 1}$ & $\mathbf{1 0 0}$ \\
\hline
\end{tabular}

Fonte: Autoria própria

Com uma periodicidade trimestral, a Revista Licere surgiu com a intenção de discutir a temática do lazer em seus múltiplos encaminhamentos a partir da ótica da multidisciplinaridade. Helder Ferreira Isayama, um dos fundadores da revista, afirma que a preocupação que pairava sobre os editores e pesquisadores do período de criação da revista (1998) era de que mesmo havendo grande volume de produção no âmbito das ciências do esporte, ainda não era seguro contar com um fluxo de artigos de qualidade para manter a revista que ambicionava contribuir com a consolidação das investigações sobre o tema (lazer), enquanto no campo internacional, esse debate já estava consolidado (ISAYAMA; MELO, 2014).

noção/ferramenta importante para entender a lógica do mundo social mediante a teoria da prática de Pierre Bourdieu. Conforme lembra então esse autor, a illusio é resultante do próprio interesse que os participantes de um campo têm nas disputas internas a este. Além disso, a illusio pode ser entendida como o conhecimento prático que permite ao agente mobilizar as ações organizadas em seu habitus" (SOUZA, 2014, p. 154). 
Dessa forma, a fim de fomentar a discussão sobre o conceito de lazer no Brasil, a Revista Licere convidou diversos editores para refletir e debater acerca dos estudos realizados em território nacional. Foi assim que esse periódico tomou corpo e começou a receber diversos estudos associados ao campo do lazer. Diante de sua flexibilidade, a Licere se destacou por receber diversas temáticas, talvez por isso a revista acolheu tantos empreendimentos sobre JEs nos últimos anos, ainda que o tema não orbitasse tanto no plano do lazer, como podemos verificar no quadro 1 adiante. Em síntese, a Licere tem-se evidenciado como uma revista aberta a investigações diferentes e heterodoxas. Daí o periódico ter contribuído sistematicamente para a difusão dos JEs como um subcampo relativamente novo de pesquisa na área.

Outro periódico que tem sido palco para as publicações dos JEs no Brasil é a Revista Motrivivência. A plataforma em questão constituiu-se como um meio de divulgação científica do campo do conhecimento que engloba Educação Física, Esporte e Lazer. Tem periodicidade quadrimestral e está vinculada à Universidade Federal de Santa Catarina. A revista se destaca pelo enfoque ao pluralismo de ideias e pela abertura para interdisciplinaridade em suas publicações. Além disso, é oportuno mencionar que é possível localizar debates na área da Educação Física e áreas afins que acabam por tratar de temas como a cultura corporal e suas interfaces frentes às ciências humanas e sociais. É dentro desta agenda que os JEs se tornaram uma pauta de discussão na Motrivivência.

Pensando numa estrutura estruturada dos periódicos que compõem nossa análise, em uma posição intermediária estão as Revista Brasileira de Ciências do Esporte (RBCE), Revista Motriz e a Revista Movimento, todas com seis (06) textos sobre JEs, totalizando $43,8 \%$ das obras analisadas. A RBCE, sob a responsabilidade do Colégio Brasileiro de Ciências do Esporte, é atualmente gerenciada pelo Programa de Pós-Graduação em Educação Física da Universidade de Brasília (UNB), em parceria com a Elsevier, uma das principais editoras internacionais de periódicos na área da ciência, tecnologia e saúde. Com a aceitação de publicação em três idiomas (português, inglês e espanhol), é passível de se perceber que, ao analisar a política da revista, existe uma preocupação em divulgar trabalhos que tenham como intenção, discutir e trazer questões empíricas rigorosas, além de debates teóricos sobre os temas referentes ao campo da Educação Física e a Ciência do Esporte, nos levando a concluir que o debate sobre JEs contribuem com a proposta levantada pelo periódico 5 .

\footnotetext{
${ }^{5}$ Informações retiradas do site: $<\mathrm{http}: / /$ www.revista.cbce.org.br $>$
} 
Já a Revista Motriz é um periódico trimestral, publicado pelo Departamento de Educação Física e Instituto de Biociências do Campus de Rio Claro, pertencente a Universidade Estadual Paulista. A primeira edição da revista foi lançada em 1995 e, até o ano de 2001, apresentava periodicidade semestral, publicando aproximadamente 15 artigos originais por ano. A partir do ano de 2002, torna-se trimestral e passa a publicar aproximadamente 25 artigos originais por ano. Ainda diante desse crescimento, a revista aumentou o volume de publicação, com o intuito de obter a indexação em bases de maior impacto. Nessa direção, a Motriz passou a publicar quatro números por ano, com uma média de 40 artigos por volume. Também com a política de livre acesso, este periódico permitiu o acesso gratuito e irrestrito ao seu conteúdo ${ }^{6}$. Essa política de ampliação nos fez compreender o motivo dos JEs serem um dos temas presentes nos editoriais recentes. Ao se colocar como uma revista que permite um diálogo com vários campos de saber, as pesquisas sobre JEs abrem um leque de questões importantes para serem debatidas e compartilhadas para um maior grupo de pesquisadores, nos levando a pensar que a revista Motriz se tornou um lugar interessante para publicações devido à sua pluralidade de discussões.

A Revista Movimento pertence à Escola de Educação Física e Dança da Universidade Federal do Rio Grande do Sul. Fundada em 1994, este periódico aborda temas relacionados ao campo da Educação Física em consonância com questões das Ciências Humanas e Sociais. Juntamente com a Revista Brasileira de Medicina do Esporte, possui qualis A2 em Educação Física, sendo as duas revistas, portanto, de grande importância para a divulgação acadêmico-científica nacional da área.

Ainda que em uma posição inferior, vale mencionar que a Revista Pensar a Prática tem recebido estudos de JEs e que, no decorrer do tempo, o periódico poderá também ser uma plataforma de discussão dessa temática. Nesse sentido, ainda que tenham sido localizados apenas quatro textos, denota-se que a Pensar a Prática tem cedido espaço a esse tipo de discussão. Em linhas gerais, a Revista Pensar a Prática publica artigos relacionados ao campo acadêmico e profissional da Educação Física. Originalmente, esse periódico atendia apenas o curso de Especialização em Educação Física Escolar e à Graduação, sendo um local de discussão da prática pedagógica local ${ }^{7}$. Atualmente, possui enfoque em questões relativas à Educação Física, ao Esporte e ao Lazer, vinculada ao campo de conhecimento da Educação Física e das Ciências do Esporte.

\footnotetext{
${ }^{6}$ Informações retiradas do site: $<$ http://www.scielo.br/img/fbpe/motriz/paboutj.htm>

${ }^{7}$ Informações retiradas de: https://www.revistas.ufg.br/fef/about/editorialPolicies\#focusAndScope
} 
Fazendo uma breve digressão e pensando na lógica que permite interpretar de maneira relacional a estrutura do campo (SOUZA; MARCHI JÚNIOR, 2017) e também nos usos do capital simbólico, embasados na teoria de Pierre Bourdieu, os seis (06) trabalhos encontrados na Revista Movimento parecem agregar (em relação ao capital simbólico específico) maior notoriedade quando comparado aos demais textos elencados, devido à classificação qualis superior da revista frente as demais, mesmo ocupando uma posição central em nossa estrutura estudada. Este capital simbólico, consegue conferir legitimidade dentro do campo, se constituindo num "[...] poder simbólico, capaz de produzir efeitos reais" (BOURDIEU, 2004, p. 15). O capital simbólico agregado é amplo e tem a capacidade de transitar em outros campos sem "perder todo o seu potencial", assegurando-se o seu reconhecimento (BOURDIEU, 1990).

Dando prosseguimento à exposição, quando tratamos a respeito da natureza dos trabalhos coletados, constatamos que 30 dos 41 textos avaliados são artigos originais e sete (07) deles são ensaios, totalizando $90,3 \%$ de todas as publicações nos periódicos. Isso, por sua vez, sugere que a preocupação dos pesquisadores que submetem trabalhos sobre a temática nos periódicos selecionados é apresentar um material de discussão mais denso do ponto de vista empírico e teórico. O restante da porcentagem equivale a resumos e resenhas acerca da temática, textos em que o esforço de discussão teórica é menor. O total geral desse resultado está descrito no quadro 1.

Quadro 1: Frequência relativa e absoluta do tipo de publicação e classificação

\begin{tabular}{|l|c|c|}
\hline \multicolumn{1}{|c|}{ Tipo } & & $\mathbf{\%}$ \\
\hline Artigo Original & 30 & 73,2 \\
\hline Ensaio & 07 & 17,1 \\
\hline Resumo & 03 & 07,3 \\
\hline Resenha & 01 & 02,4 \\
\hline \multicolumn{1}{|c|}{ Classificação } & & $\mathbf{\%}$ \\
\hline Histórico-social & 15 & 36,6 \\
\hline Jogos Digitais & 12 & 29,3 \\
\hline Exergames & 09 & 21,9 \\
\hline Lazer & 05 & 12,2 \\
\hline
\end{tabular}

Fonte: Autoria própria

Já quando nos remetemos à classificação proposta em nosso estudo, observamos uma dominância dos estudos considerados Histórico-sociais - aqueles que tiveram por objetivo analisar a interação humano-máquina e/ou estudos epistemológicos causados por mudanças socioculturais na cibercultura. Na sequência, aparecem os trabalhos inseridos no contexto dos Jogos Digitais, que são os empreendimentos que apresentam uma relação direta e/ou experiência com algum JE, em especial, quando ocorre a transferência de 
aprendizagem do virtual para o real. Em seguida, observam-se as categorias Exergames e Lazer, que tem dimensão atrelada ao aspecto de atividade corporal e do prazer, quando visto pelo eixo temático do lazer.

Ao propor tal classificação, nosso objetivo foi reunir indícios sobre a lógica que orienta a construção dessa agenda de pesquisa no campo, ampliando o entendimento sobre a temática. Dessa maneira, e com base nos dados descritos, podemos destacar que, a partir de um olhar diacrônico, ocorreu um avanço considerável nas pesquisas sobre JEs, deslocando-o, assim, do imaginário vinculado a uma prática sem importância para um patamar mais sofisticado de teorização, em um contexto atual da discussão acadêmicocientífica no campo da Educação Física brasileira. Tal resultado demonstra que os JEs têm sido explorados em diferentes vias, indicando níveis maiores de reflexividade para com os variados eixos articuladores desse subcampo de pesquisa.

Cabe destacar que o fazer científico reflexivo, conforme sugerem Bourdieu; Chamboredon e Passeron (1999) no livro "A profissão de sociólogo"» é uma conquista progressiva de campos com maior autonomização. Segundo os autores, para que ocorra uma objetivação da ciência, a mesma não pode estar baseada simplesmente na objetividade do pesquisador isolado. Nessa dinâmica, os índices de reflexividade e de vigilância epistemológica ${ }^{9}$ se complementam no campo. Em outras palavras, para uma ciência com

\footnotetext{
8 " [...] este livro representa exemplarmente uma das vertentes críticas que derrubaram o predomínio da sociologia funcionalista norte-americana, a partir da década de 1960, tornando-se desde então referência para o entendimento da prática sociológica [...] Os autores querem transmitir "um sistema de hábitos intelectuais" que fundamenta a ciência sociológica, operando como princípios racionais de todo o processo de investigação, ampliando, desse modo, a razão até a lógica da invenção. A concepção supõe uma unidade epistemológica entre as ciências, que permite transferir o saber epistemológico das ciências naturais para as ciências humanas, e convergência epistemológica das grandes teorias sociológicas clássicas, em torno de uma teoria do conhecimento sociólogo. Nessa perspectiva, muitos textos epistemológicos e teóricos de filósofos e cientistas de diferentes áreas, compõem o volume e devem ser lidos junto com a exposição principal, segunda suas indicações, para interiorização desse modo de ver a lógica da produção de conhecimento racional do social" (GARCIA, 2017, p. 299).

9 “Com rigor, cabe ressaltarmos que a solução metodológica apresentada por Bourdieu para resolver o dilema entre, de um lado, o empirismo cego e, de outro, a teoria sem controle, consiste na prática daquilo que ele entende por "vigilância epistemológica", e que, sucintamente falando, trata-se de um método de sondagem onde o pesquisador procura trabalhar a teoria do conhecimento sociológico e a teoria do sistema social de forma envolvente, relacional e reflexiva. Essa vigilância epistemológica, por sua vez, exige ainda uma ruptura com aquelas prenoções, ou melhor, pré-construções que cerceiam e organizam o mundo social, as quais, de forma muito perigosa e envolvente, conduzem os pesquisadores a tomarem falsas evidências e falsas certezas como se fossem verdadeiras. No entanto, essa rigorosidade instaurada pela vigilância epistemológica (que a priori é bem contrário de rigidez), não significa que o pesquisador deva desprezar ou então romper com as materialidades empíricas que são pertinentes aos objetos de pesquisa, mas, indubitavelmente, se atentar para o processo de construção dos mesmos prezando pela objetividade teórica na interpretação do universo empírico e, acima de tudo, não tratando os "fatos" como "dados", ou seja, como um corpo de conhecimentos que materializa de tal modo a realidade a ponto de não demandar um tratamento teórico mais refinado e específico. Dito em termos mais sintéticos, Bourdieu insiste é na conversão intelectual, na ruptura com noções estereotipadas e na recusa de juízos de valor (sejam aqueles provenientes do senso comum ou, então, dos
} 
eficácia se faz necessário uma dialética entre as trocas constantes de argumentos.

[...] tudo leva a considerar que a troca generalizada de críticas em que, como no sistema de trocas matrimoniais com o mesmo nome, A crítica B que criticaria $\mathrm{C}$ que, por sua vez, criticaria $\mathrm{A}$, constitui um modelo mais favorável a uma interação orgânica do meio científico do que, por exemplo, o clube de admiração mútua como troca restrita de serviços ou, o que não é de modo algum mais válido, a troca de polêmicas rituais pelas quais os adversários cúmplices consolidam mutuamente os respectivos estatutos (BOURDIEU; CHAMBOREDON; PASSERON, 1999, p. 95).

A troca constante de críticas mútuas e de maneira respeitosa em favor de um fazer científico tal como os autores pontuam, além do próprio movimento legítimo por busca de capital e posições dentro do campo, parecem ser ferramentas fundamentais para avançar em favor de uma ciência reflexiva. Nesse sentido, ao avanço das pesquisas sobre JEs é importante somar a operacionalização de uma maior vigilância epistemológica, que tenha por objetivo controlar o objeto de estudo e romper com o senso douto, reconhecendo que preconcepções doutas existem e que precisam ser controladas. Por fim, é interessante também entender a lógica do campo, para assim, ou só assim, fazer uma ciência consciente e consistente, efetiva e eficaz (BOURDIEU, 1996, 2004, 2014).

Dando continuidade ao nosso percurso empírico, apresentamos na tabela 2 os principais agentes que foram encontrados nos estudos em torno da temática investigada. Ao traçarmos um panorama histórico-sociológico sobre as revistas e, ao mapear os pesquisadores, podemos verificar e constatar uma rede de intelectuais e um nicho de circulação da produção que ocorre nesse subcampo acadêmico-científico da Educação Física brasileira.

Tabela 2: Frequência relativa e absoluta dos principais pesquisadores encontrados sobre JEs.

\begin{tabular}{lcc}
\hline Autores & \% \\
\hline Alex Branco Fraga & 02 & 02 \\
Ana Márcia Silva & 02 & 02 \\
Ana Paula Salles da Silva & 04 & 04 \\
Elisabeth Rose Assumpção Harris & 02 & 02 \\
Fernando Renato Cavichiolli & 04 & 04 \\
Gilson Cruz Junior & 06 & 06 \\
Giovani de Lorenzi Pires & 02 & 02 \\
Guy Ginciene & 02 & 02 \\
Leoncio José de Almeida Reis & 04 & 04 \\
Mateus David Finco & 03 & 03 \\
Sara Quenzer Matthiesen & 02 & 02 \\
Outros & 67 & 67 \\
\hline Total & $\mathbf{1 0 0}$ & $\mathbf{1 0 0}$ \\
\hline
\end{tabular}

universos científicos) como condições de urgência para que se instaure a vigilância epistemológica no campo da sociologia e de modo que os objetos de pesquisa possam ser mais bem construídos e problematizados (SOUZA, 2010, p. 28-29). 
Fonte: Autoria própria

Em uma rápida visita sobre as trajetórias acadêmicas desses pesquisadores, realizamos a coleta das informações na base de dados da "Plataforma Lattes" ", com o objetivo de verificar os temas de pesquisa de cada agente e encontrar possíveis pontos de conexão entre eles. Nossa hipótese é de que existe um nicho de produção e que a rede de circulação do conhecimento científico sobre JEs está concentrada em torno destes pesquisadores no campo da Educação Física. Como ressalta Bourdieu, os campos sociais não são concebidos como um domínio isolado, mas sim como estruturas que se interligam a outros domínios distintos. Por meio da coleta de dados, podemos perceber alguns pontos de interseção entre eles, corroborando com a hipótese levantada.

Utilizando como exemplo o caso da pesquisadora Ana Paula Salles da Silva, percebemos que a autora construiu sua carreira de pesquisadora sendo orientada por Ana Márcia Silva, outro agente com significativos estudos no campo em discussão. Segundo os dados coletados, a relação socioacadêmica entre essas duas agentes teve início formal em meados de 2003, quando Ana Márcia Silva passou a orientá-la no trabalho do curso de especialização em Educação Física Escolar pela Universidade Federal de Santa Catarina. Ao longo dos anos, Ana Márcia Silva se torna figura constante da trajetória acadêmica de Ana Paula Salles, lhe orientando tanto no Mestrado como também no Doutorado. Interessante é que, ao orientar Ana Paula Salles em pesquisas sobre JEs, Ana Márcia Silva passa a publicar pesquisas com essa temática, dando indícios de que foi a partir desta orientação que ela entrou nesse cenário de discussão acadêmico-científica. Podemos verificar aqui uma possível relação transcrita, por meio de um habitus científico, aquele que Bourdieu descreve como uma teoria realizada e incorporada em um conjunto de disposições, no qual se pode incluir a linguagem corporificada e alicerçada na escrita científica, um senso prático da orientação teórica que necessita de uma compreensão cognitiva, interpretação simbólica e ambientação cultural (BOURDIEU, 2001, 2004).

Outra questão que foi possível perceber ao mapear a carreira acadêmica desses pesquisadores é a vinculação de alguns aos periódicos com maior produção de JEs referente a tal assunto. Nessa esteira, verificamos os casos de Alex Branco, Ana Márcia Silva e Giovani de Lorenzi Pires, pesquisadores que tiveram importantes funções dentro dos próprios periódicos. Alex Branco foi editor-chefe da Revista Movimento (2012-2016), além de ter participado como editor da Revista Brasileira de Ciências do Esporte. Ana Márcia

\footnotetext{
${ }^{10}$ Informações retiradas do site currículo lattes: http://lattes.cnpq.br/
} 
Silva tem uma participação mais ampla, pois é editora-chefe da Revista Pensar a Prática e membro do corpo editorial, além de revisora de vários outros periódicos. Por fim, face a esta linha de raciocínio, temos Giovani de Lorenzi Pires, coeditor da Revista Motrivivência. Quando somamos a porcentagem de produção das revistas que estes três pesquisadores fazem parte, temos o montante de $42,2 \%$, ou seja, quase metades das publicações de JEs estão nas revistas em que são editores ou coeditores.

Os demais pesquisadores não necessariamente fazem parte de comissões editoriais, porém estão vinculados a grupos de pesquisas das principais Universidades do país que possuem parceria com estas revistas, como é o caso do Laboratório Physis de Pesquisa em Educação Física e Laboratório e Observatório da Mídia Esportiva (LABOMIDIA/UFSC). Essa aproximação entre os pesquisadores em grupos de pesquisa e o trabalho prestado nos periódicos refletem um pouco o que sintetizamos no gráfico 1 e 2 .

Gráfico 1: Ordem cronológica dos trabalhos sobre Jogos Eletrônicos nos periódicos científicos da Educação Física

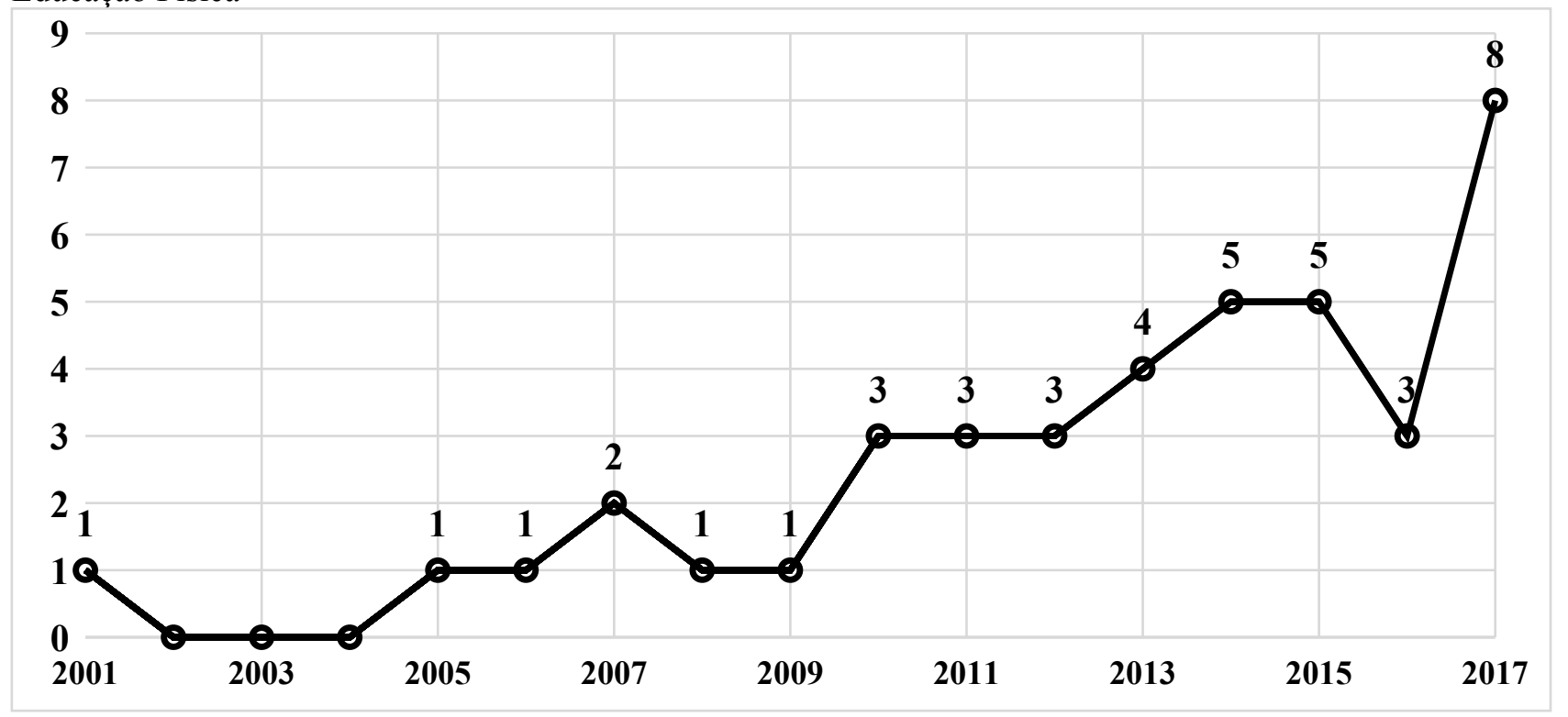

Fonte: Autoria própria 
Gráfico 2: Instituições responsáveis pelas publicações a respeito dos Jogos Eletrônicos nos periódicos científicos da Educação Física

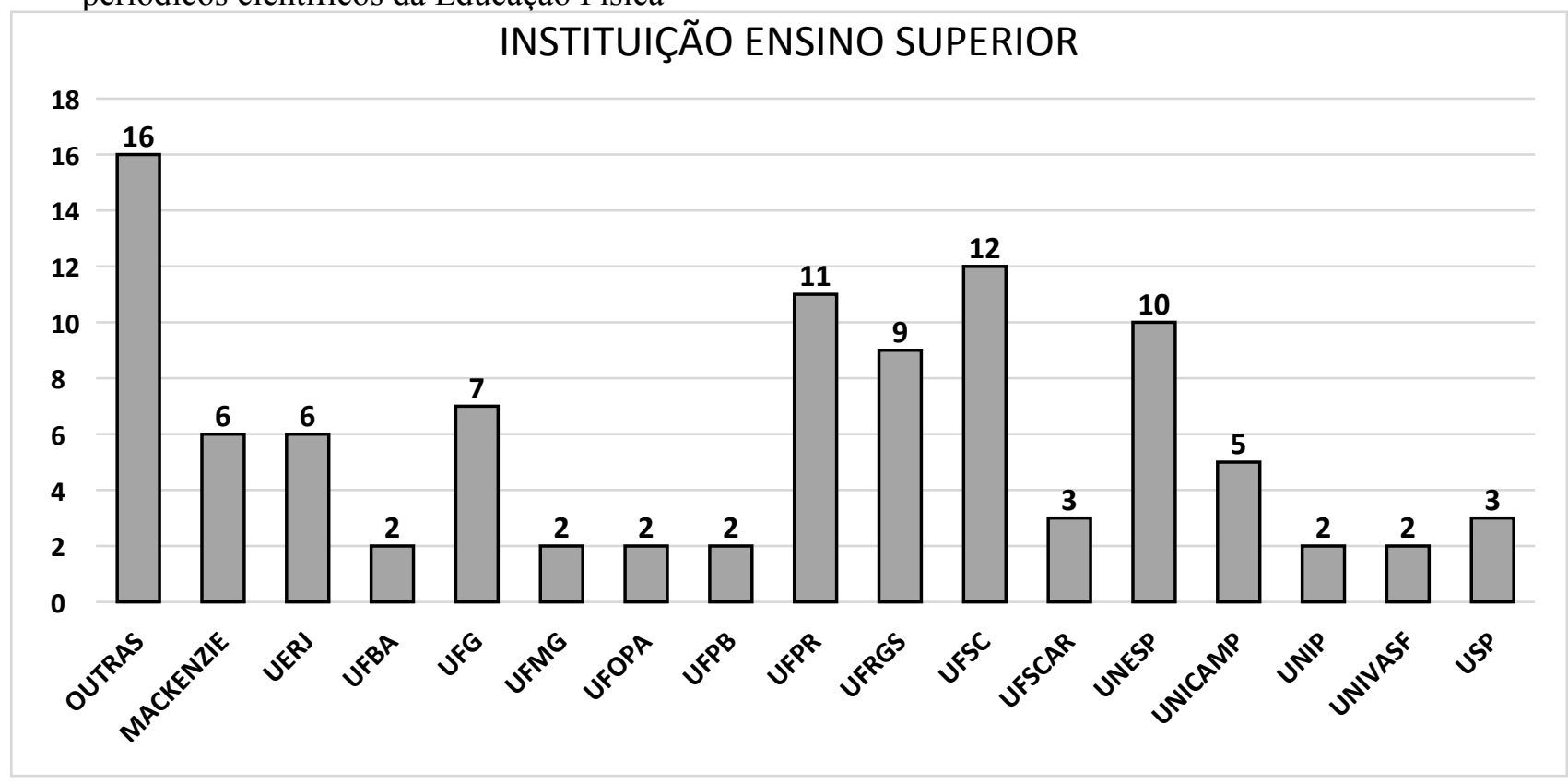

Fonte: Autoria própria

No intuito de avançar na compreensão dessas redes socioacadêmicas temporais e estruturais, recorremos complementarmente ao referencial de Norbert Elias (1897-1990) ${ }^{11}$, que se propõe a romper com a dicotomia indivíduo e sociedade a partir do conceito de figuração de modo a produzir uma compreensão mais integrativa e articulada dessa dinâmica. Ao mapear as redes acadêmicas, nossa contribuição aqui foi a de demonstrar como as relações de interdependência (em termos eliasianos), no qual "o indivíduo está ligado aos outros por um fenômeno de dependência recíproca" (ELIAS, 2001, p. 56) são importantes para a formação de um habitus científico individual (em termos bourdieusianos), que passa pela incorporação de um conjunto de disposições e particularidades, uma illusio que carrega heranças históricas, depositada nos agentes acerca dos sentidos de linguagem e corporificada na escrita científica (BOURDIEU, 2004).

Ao analisar as datas de publicação destes artigos (gráfico 1) é visível o crescimento das pesquisas sobre JEs na presente década. O aumento dessas pesquisas parece estar diretamente associado ao debate epistemológico contemporâneo. Como podemos verificar, no início do século XXI é praticamente exígua a produção sobre essa temática. Imaginamos

\footnotetext{
${ }^{11}$ Norbert Elias foi um sociólogo alemão nascido em 1897 na cidade de Breslau e é um dos principais sociólogos do século XX. Todavia, seu reconhecimento na área das ciências sociais se deu tardiamente, em particular, décadas após a publicação de algumas de suas obras. Entre elas, destacam-se O Processo Civilizador em dois volumes e a Sociedade de Corte, que embora produzidas na década de 1930 só tiveram reconhecimento mais amplo na década de 1970. Para conhecer um pouco mais sobre o autor, ver: ELIAS, Norbert. Norbert Elias por ele mesmo. Tradução de André Telles. Rio de Janeiro: Jorge Zahar, 2001.
} 
que esta ausência se deu pela representação que esse assunto detinha neste momento histórico, como um objeto de pesquisa de pouca relevância ou importância no cenário acadêmico-científico. A partir do ano de 2010, torna-se perceptível o aumento de pesquisas na área, concomitante à noção e tratamento dos jogos não só em sua esfera de lazer, mas também como prática esportiva. Analisando de forma relacional essa curva de crescimento com outras áreas do conhecimento, nossos dados se aproximam aos resultados encontrados por Alves (2013), que procurou investigar a produção do conhecimento em torno dos JEs na área da Educação. Segunda a autora, a partir dos anos de 2006 e 2007 ocorre um crescimento significativo no que refere à produção de trabalhos científicos sobre a temática dos JEs na área de Educação.

Ao deparar com a noção de que os JEs seriam práticas de lazer, grupos de pesquisas passam a se debruçar sobre a temática, o que acaba por refletir nos índices do segundo gráfico. Tendo um índice apenas menor que a somatória de outras IES, a UFSC é a principal instituição a publicar sobre essa agenda de discussão acadêmico-científica (gráfico 2). Este resultado é passível de compreensão, pois um número considerável de pesquisadores produtivos sobre a temática pertence ou já pertenceu a esta instituição, ou seja, 14\% da produção da UFSC sobre JEs é sintetizada na figura dos pesquisadores que detalhamos a seguir.

O primeiro caso a ser analisado é da pesquisadora Ana Márcia Silva que se graduou, especializou-se e tornou-se Mestre e Doutora pela UFSC, além de pertencer ao corpo docente da Universidade Federal de Goiás ( $5^{\circ}$ Universidade em nosso gráfico a publicar sobre JEs). Com uma trajetória semelhante, está a orientanda de Ana Márcia Silva, a pesquisadora Ana Paula Salles da Silva, que também teve sua carreira acadêmica desde a graduação até o doutorado vinculada à UFSC.

Em seguida, temos Gilson Cruz Júnior que também realizou seu Mestrado e Doutorado pela UFSC. Além de construir sua trajetória na pós-graduação dessa instituição, atualmente é integrante do Laboratório e Observatório da Mídia Esportiva (LABOMIDIA) que pertence UFSC, ou seja, esse pesquisador participa ativamente dos núcleos de produção científica dessa instituição. Giovani de Lorenzi Pires é outro pesquisador que se graduou pela UFSC. Após circular por outras universidades, Giovani retornou a UFSC para se tornar Mestre. Hoje este pesquisador é professor-associado aposentado do Departamento de Educação Física da Universidade Federal de Santa Catarina, docente e orientador credenciado no PPGEF/UFSC, além de ser pesquisador do LaboMídia pela mesma instituição. 
Por fim, outro polo de produção sobre JEs no campo da Educação Física está centrado na UFPR. Pertencente a essa instituição, encontram-se os pesquisadores Fernando Renato Cavichiolli e Leoncio José de Almeida Reis. Cavichiolli é professor do Programa de Pós-Graduação Stricto Sensu em Educação Física da UFPR e comandou setores administrativos do departamento. Já Leoncio Reis construiu sua carreira como pesquisador nesta instituição, sendo atualmente docente da UFPR-Litoral. A porcentagem de produção desses pesquisadores somados equivale a $8 \%$ sobre o montante total recortado e analisado em nossa investigação, porém, se observamos o número de produções só da UFPR, estes também são os principais nomes no quesito de produção em JEs na instituição.

\section{CONSIDERAÇÕES FINAIS}

É inegável o fato de que os JEs de maneira geral vêm tendo um crescimento expressivo nos últimos anos. No campo acadêmico-científico, os JEs seguem também um curso de crescimento, orientado por uma tendência de deslocamento do objeto da esfera de lazer para outras rotas de análise, isto é, que não apenas lhe inserem no contexto de prática de divertimento, mas em outras possibilidades de escrutínio científico, a exemplo do contexto pedagógico, histórico e esportivo, evidenciando as próprias facetas que os $e$ Sports adquirem na sociedade pós-tradicional.

Nessa esteira analítica, percebemos ainda que as redes de pesquisadores que investigam a prática tornam-se nítidas quando expostas ao método de análise que orientou nossa abordagem. Ademais, verificamos que alguns dos principais agentes divulgadores dessa agenda no campo da Educação Física possuem relação próxima ou participam dos mesmos grupos de pesquisas e instituições em que os pesquisadores estão inseridos. Como podemos observar por meio do mapeamento sistemático da literatura, existem dois polos institucionais de produção, a saber, a UFSC e a UFPR. No âmbito dessas instituições estão localizados os principais grupos de pesquisas que possuem aproximação com o tema. Diante dessa estrutura, é possível visualizar uma estreita relação entre os pesquisadores que mais produzem sobre JEs, seja por pertencerem à mesma instituição ou por fazerem parte de editoras de revistas. Dentre estas relações, destacam-se as aproximações por orientação, formação e rede de divulgação científica.

Nas relações de orientação, encontramos o caso em que a orientadora passou a pesquisar e se aproximar da temática dos JEs em função das demandas da pesquisa de sua 
orientanda. $\mathrm{Na}$ relação de formação, encontramos pesquisadores que construíram sua trajetória na mesma instituição e hoje fazem parte dos mesmos grupos de pesquisa. E, por fim, na relação de divulgação científica, estão aqueles pesquisadores ligados a corpos editoriais dos principais periódicos de Educação Física do país, o que acaba por referendar a hipótese que apresentamos no início do texto de que existe um grupo de intelectuais que estão envolvidos em uma rede de relações científicas articuladas em torno dos JEs.

Concluímos, portanto, que essas relações acadêmicas, bem como a estrutura dos periódicos científicos, são passíveis de serem observadas, por meio de uma posição no subcampo de investigações sobre JEs movida pelos agentes e influenciada pelo habitus científico, uma espécie de poder simbólico referente à circulação de ideias. Existe, além disso, uma estreita relação entre capital científico e poder simbólico, sendo que esse ajustamento "[...] a uma ordem simbólica se dá pela imposição de estruturas estruturantes que se ajustam às estruturas objetivas [...]" (HEY, 2017, p. 292). Ou seja, uma autoridade legítima sobre um determinado assunto ou uma posição superior de um periódico frente a outro (nesse caso, a produção do conhecimento sobre JEs no campo acadêmico-científico da Educação Física) tende a se construir por vias ocultas, como uma forma desconhecida de reconhecimento (CATANI et al., 2017). Nesse sentido, é que identificamos no âmbito da produção acadêmica especializada em Educação Física sobre JEs, a existência de uma lógica de legitimação dos agentes autorizados a discursarem cientificamente sobre a prática a partir do compartilhamento de um modus operandi do fazer científico (BOURDIEU, 1983, 1996, 2004).

\section{REFERÊNCIAS}

ALVES, Lynn. Games e Educação: Desvendando o labirinto da pesquisa. Revista da FAEEBA - Educação e Contemporaneidade, Salvador, v. 22, n. 40, p. 177-186, jul. 2013.

AMARAL, Bruno do. Brasileiro usa celular por mais de três horas por dia. 2016. Disponível em: https://exame.abril.com.br/tecnologia/brasileiro-usa-celular-por-mais-detres-horas-por-dia/. Acesso em: 25 de abr. 2017.

ARANHA, Gláucio. O processo de consolidação dos jogos eletrônicos como instrumento de comunicação e de construção de conhecimento. Ciências \& Cognição; Rio de Janeiro, v. 03, n. 01, p.21-62.

BARACHO, Ana Flávia de Oliveira; GRIPP, Fernando Joaquim; LIMA, Márcio Roberto de. Os exergames e a educação física escolar na cultura digital. Revista Brasileira de 
Ciências do Esporte. v. 34, n. 1, pp. 111-126. mar. 2012. http://dx.doi.org/10.1590/s010132892012000100009.

BECK, Ulrich; GIDDENS, Anthony; LASH, Scott. Modernização reflexiva: política, tradição e estética na ordem social moderna. São Paulo: Universidade Estadual Paulista, 1997.

BOURDIEU, Pierre. Pierre Bourdieu: sociologia. Org. Renato Ortiz. São Paulo: Ática, 1983.

BOURDIEU, Pierre. Coisas ditas. São Paulo: Brasiliense, 1990.

BOURDIEU, Pierre. As regras da arte: Gênese e estrutura do campo literário. São Paulo: Companhia das Letras, 1996.

BOURDIEU, Pierre. O campo econômico. Actes de la Recherche em Sciences Sociales, n. 119, v. 1, p. 48-66, set. 1997.

BOURDIEU, Pierre; CHAMBOREDON, Jean-Claude; PASSERON, Jean-Claude. A profissão de sociólogo: preliminares epistemológicas. Rio de Janeiro: Vozes, 1999.

BOURDIEU, Pierre. Meditações pascalianas. Rio de Janeiro: Bertrand Brasil, 2001.

BOURDIEU, Pierre. Os usos sociais da ciência: por uma sociologia clínica do campo científico. São Paulo: Universidade Estadual Paulista, 2004.

BOURDIEU, Pierre. A distinção: sobre a teoria da ação. São Paulo: Papirus, 2007.

BOURDIEU, Pierre. Homo Academicus. $2^{\circ}$ Edição: Santa Catarina: Universidade Federal Santa Catarina, 2013.

BOURDIEU, Pierre. Sobre o estado. São Paulo: Companhia das Letras, 2014.

CATANI, Afrânio Mendes. Lições de aula. IN: CATANI, Afrânio Mendes et al.

Vocabulário Bourdieu. Belo Horizonte: Autêntica, 2017, p. 249-250.

ELIAS, Norbert. Norbert Elias por ele mesmo. Rio de Janeiro: Jorge Zahar, 2001.

GARCIA, Gemignani Sylvia. A profissão de sociólogo: Premissas epistemológicas. IN: CATANI, Afrânio Mendes et al. Vocabulário Bourdieu. Belo Horizonte: Autêntica, 2017. p. 298-301.

GIDDENS, Anthony. Modernidade e identidade. Rio de Janeiro: Jorge Zahar, 2002.

HEY, Ana Paula. Poder Simbólico (o). IN: CATANI, Afrânio Mendes et al. Vocabulário Bourdieu. Belo Horizonte: Autêntica, 2017. p. 295.

MACY, Seth. Faturamento de $\boldsymbol{e}$-Sports em 2015 supera os US\$ 700 milhões. 2015. Disponível em: http://br.ign.com/esports/10693/news/faturamento-de-e-sports-em-2015supera-os-us-700-milhoes. Acesso em: 04 abr. 2017. 
ISAYAMA, Helder Ferreira; MELO, Victor Andrade de. Licere: uma revista brasileira de lazer. Revista Brasileira de Ciências do Esporte, v. 36, n. 4, p. 773-779, out. 2014. http://dx.doi.org/10.1016/j.rbce.2014.11.011.

LÉVY, Pierre. O Que é Virtual? Rio de Janeiro: Editora 34, 1996.

MANCUSO, Filippo. Mercado de games fatura cerca de US\$1 bilhão por ano no Brasil. 2015. Disponível em: http://g1.globo.com/jornal-daglobo/noticia/2015/10/mercado-de-games-fatura-cerca-de-us-1-bilhao-por-ano-nobrasil.html. Acesso em: 04 abr. 2017.

ORTIZ, Renato. Introdução. IN: BOURDIEU, Pierre. Pierre Bourdieu: sociologia. São Paulo: Ática, 1983. p. 06-37.

OLIVEIRA, João José. Indústria de jogos eletrônicos muda com o consumidor. 2017. Disponível em: http://www.valor.com.br/empresas/5133124/industria-de-jogos-eletronicosmuda-com-o-consumidor. Acesso em: 25 abr. 2018.

STEWART, James. Pessoas gastam no Facebook quase o mesmo tempo que para comer e beber. 2016. Disponível em: http://www1.folha.uol.com.br/mercado/2016/05/1768613-pessoas-gastam-no-facebookquase-o-mesmo-tempo-que-para-comer-e-beber.shtml. Acesso em: 25 abr. 2018.

SOUZA, Juliano de. O xadrez em xeque - uma análise sociológica da "história esportiva" da modalidade. 2010. 191 f. Dissertação (Mestrado). Curitiba, Universidade Federal do Paraná, Curitiba, 2010.

SOUZA, Juliano de; MARCHI JÚNIOR, Wanderley. Bourdieu e a sociologia do esporte: contribuições, abrangência e desdobramentos teóricos. Tempo Social. São Paulo, v. 29, n. 02, p. 243-286, ago. 2017. http://dx.doi.org/10.11606/0103-2070.ts.2017.106962.

\section{NOTAS DE AUTOR}

\section{AGRADECIMENTOS}

Agradecemos a Coordenação de Aperfeiçoamento de Pessoal de Nível Superior (CAPES).

CONTRIBUIÇÃO DE AUTORIA - Não se aplica.

FINANCIAMENTO - Não se aplica.

CONSENTIMENTO DE USO DE IMAGEM - Não se aplica.

APROVAÇÃO DE COMITÊ DE ÉTICA EM PESQUISA - Não se aplica.

CONFLITO DE INTERESSES - Não há conflito de interesse nesse estudo. 


\section{LICENÇA DE USO}

Os autores cedem à Motrivivência - ISSN 2175-8042 os direitos exclusivos de primeira publicação, com o trabalho simultaneamente licenciado sob a Licença Creative Commons Attribution Non-Comercial ShareAlike (CC BY-NC SA) 4.0 International. Estra licença permite que terceiros remixem, adaptem e criem a partir do trabalho publicado, desde que para fins não comerciais, atribuindo o devido crédito de autoria e publicação inicial neste periódico desde que adotem a mesma licença, compartilhar igual. Os autores têm autorização para assumir contratos adicionais separadamente, para distribuição não exclusiva da versão do trabalho publicada neste periódico (ex.: publicar em repositório institucional, em site pessoal, publicar uma tradução, ou como capítulo de livro), com reconhecimento de autoria e publicação inicial neste periódico, desde que para fins não comerciais e compartilhar com a mesma licença.

\section{PUBLISHER}

Universidade Federal de Santa Catarina. Programa de Pós-Graduação em Educação Física. LaboMídia - Laboratório e Observatório da Mídia Esportiva. Publicado no Portal de Periódicos UFSC. As ideias expressadas neste artigo são de responsabilidade de seus autores, não representando, necessariamente, a opinião dos editores ou da universidade.

\section{EDITORES}

Mauricio Roberto da Silva, Giovani De Lorenzi Pires, Rogério Santos Pereira.

\section{HISTÓRICO}

Recebido em: 10 de outubro de 2018.

Aprovado em: 17 de fevereiro de 2019. 